\title{
Biological activity of carbon nanoparticles produced in combustion process
}

In the recent years industrial applications of carbon allotropes such as carbon nanotubes (CNTs) and graphene have been tested extensively, thus justifying research on the environmental impact these materials have. In the current paper we compare EDS spectroscopy results of a cabin filter used in a car to a filter used in an air purifier inside a residential space. The contaminants adsorbed on the carbon nanoparticles trapped in both types of filters allows for determining of their source of origin demonstrating clearly the dominant role of non-road emissions in Poland. Finally we present the experimental study on the growth of plants on substrates intentionally enriched with CNTs.

Key words: carbon nanotubes; nanoparticles, environment

\section{Introduction}

The emission of carbon nanoparticles has always accompanied many natural processes such as, for example, forest fires [1-3]. Undoubtedly, the discovery of nanometric particles such as carbon nanotubes and graphene and intensive work on their industrial applications which have intensified especially after 2000 can significantly influence the circulation and prevalence of nanomaterials in nature [4-7]. Regardless of purposeful attempts to use carbon nanomaterials fossil fuel combustion processes are a significant source of their emission. In the studies presented in [8] a strong correlation was found between the concentration of CNT in the lungs of children living in Paris and the presence of gas stoves in their flats. In other works it was shown that vehicle combustion engines are also a source of emission of carbon nanotubes, especially in the case of gas engines [9-12]. These nanotubes have been treated so far as a component of soot, particulate matter containing mainly amorphous carbon and adsorbed impurities. Indeed, if you compare the combustion process in the engine cylinder, you can find similarity to the CVD process, which is the most popular method of growing CNTs. It is also understandable that the nanotubes grown in the combustion process of the piston engine are characterized by a very short length, resulting from the short duration of individual combustion cycles. In studies [13], it was shown that CNT can be intentionally grown on the surface of a cooled metal plate introduced into the engine exhaust gas stream.

The research carried out thus far does not allow to clearly determine the impact of carbon nanomaterials on biological processes, let alone the human body. On the one hand, they imply some extent of carcinogenic effects on animals when inhaled. It can be assumed that the carcinogenic effect is associated with the presence of precursors to the growth of nanotubes or other metal nanoparticles such as iron, nickel, cobalt, which can easily decorate the surface of nanotubes. On the contrary, nanotubes that were cleaned of any metal nanoparticles contamination were successfully used in the purification systems of manned spacecraft [14]. The successes of clinical trials are reported, where CNTs were deliberately introduced into the human body in place of the missing bone fragments in cases of multiple fractures; CNT serves in this case as a scaffold which initiates the process of bone healing [15]. In a recent study, it was shown that CNT and graphene can be deliberately introduced into the body of spiders, which incorporate them into the web material causing their webbing to exhibit increased strength and durability [16].

The effect of the carbon nanotubes presence in the substrate on the growth of plants and their presence in parts of plants such as leaves or fruits is still not fully understood. Research carried out by Khodakovskaya et al. prove the positive effect of the carbon nanotubes presence on the acceleration of germination and further growth of tomato plants [17]. In other experiments the same authors showed the effect that carbon nanotubes presence has when introduced into the soil when watering tomatoes to their phenotype change. Plants of tomato grown on soil with a CNT addition produced the same amount of leaves, but twice as many flowers and fruits than plants growing in ordinary soil [18].

Other studies carried out on soybeans, maize and beans show a diverse plant response to the presence of carbon nanotubes. The inhibition of small root growth has been proven for all plant species studied. Inhibition of root growth was associated with reduced metabolic activity of root tissue and decreased nitrate uptake, which can be attributed mainly to the smaller root system. The results showed that even under standard growth conditions, largely excluding external factors, plant responses to MWCNT exposure show differences depending on the plant species, but also on the physiological state and stage of development of the individual plants. Detailed analyses made in the case of soybeans have shown that oxidative stress induced by the presence of CNT is the main determinant of inhibition of root growth. Due to the fact that the damage to the plant could be reversed by supplementing the root system with zinc, it was considered that the presence of CNT can immobilize the internal flow of micronutrients. Thus, some environmental phytotoxicity of CNT can be demonstrated along with the negative effect of CNT use in agriculture [19]. 
In order to verify the positive effect of the carbon nanotubes presence in the substrate, an experiment was carried out cultivating cress on a substrate enriched with carbon nanotubes. Garden cress (Lepidium sativum L.) is a species of an annual plant from the Brassica family. In Poland, it occurs under the name of curly cress or pepper grass, which is related to watercress. It is a plant characterized by a high tolerance to various climatic and soil conditions, readily growing with a small amount of irrigation, poor soil and lack of specialized cultivation knowledge. Easy cultivation and tolerance of various climatic conditions gives the opportunity to grow and test it all over the world. The cress can be grown at home and in a garden. It requires the soil or substrate to maintain humidity because the plant is quite shallowly rooted [19]. The fruit of the coleoptera is 5-6 mm long and contains two smooth, ovoid-shaped seeds, pointed strongly in the reddish-brown colour. With dimensions 2.2 $2.2 \mathrm{~mm}$ long, $1.0-1.5 \mathrm{~mm}$ wide and $0.6-1.4 \mathrm{~mm}$ thick [20].

Garden cress contains large amounts of iron, calcium, folic acid as well as vitamins $\mathrm{A}$ and $\mathrm{C}$. It is characterized by a high protein content (about 25\%) including: glutamic acid, leucine and methionones. The seeds contain $22-23 \%$ of oil, which used to be extracted for food and technical purposes. Oil of higher purity can be obtained by pressing shelled seeds or seeds with the cover partially removed [21].

Cress leaves have the following composition: $5.8 \%$ of proteins, $1 \%$ of fats, $87 \%$ of carbohydrates, $2.2 \%$ of mineral compounds, including calcium $(0.36 \%)$, and phosphorus $(0.11 \%)$. There are also trace elements of: iron, nickel, cobalt, iodine, vitamin A, niacin, thiamine, ribofalvinum, and ascorbic acid. Seeds, in turn, contain mainly alkaloids as well as calcium iron, carotene, riboflavin, uric acid, cellulose, phosphorus, thiamine and niacin. The seed oil contains stearic acid, palmitic acid, linoleic behenic acid, oleic acid, peanut oil, lignoceric acid, benzyl isothiocyanate, benzyl cyanide, sterol and sitosterol [20].

The goal of the research was to determine the effect of the substrate with a carbon nanotube layer on the height of the growing cress seedling.

\section{Carbon nanoparticles in the atmosphere}

The main sources of carbon nanoparticles emission to the atmosphere are, among others, vehicle combustion engines, industrial processes and fuel combustion in domestic heating furnaces. The last of the sources plays a marginal role in the developed countries of Western Europe, where using solid fuels for heating purposes has been banned for a long time now. Compared to this, Polish villages and cities are unusual, in that household fuel burners using solid fuel are commonly used for heating, low-quality Sulphur containing fuels are burnt often and there is still public and legal consent for general waste incineration in rural areas. Figures 1 and 2 present a macroscopic and microscopic picture, respectively, of a household filter for air purification with pollution accumulated in just a few days of operation during the heating season in a Polish house in a rural area.

Figure 3 is a comparison between the spectroscopy results of the filters shown in the previous figures. Carbon nanoparticles generated in the combustion process adsorb chemical contaminants on their surface, hence the chemical

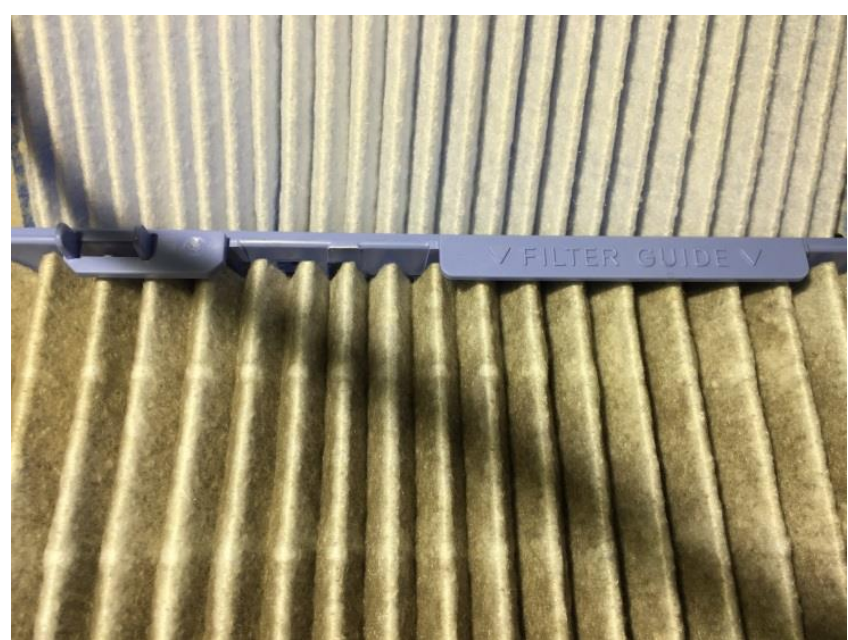

Fig. 1. The filter surface after a few days of operation as domestic air purifier, in the background a new filter for comparison
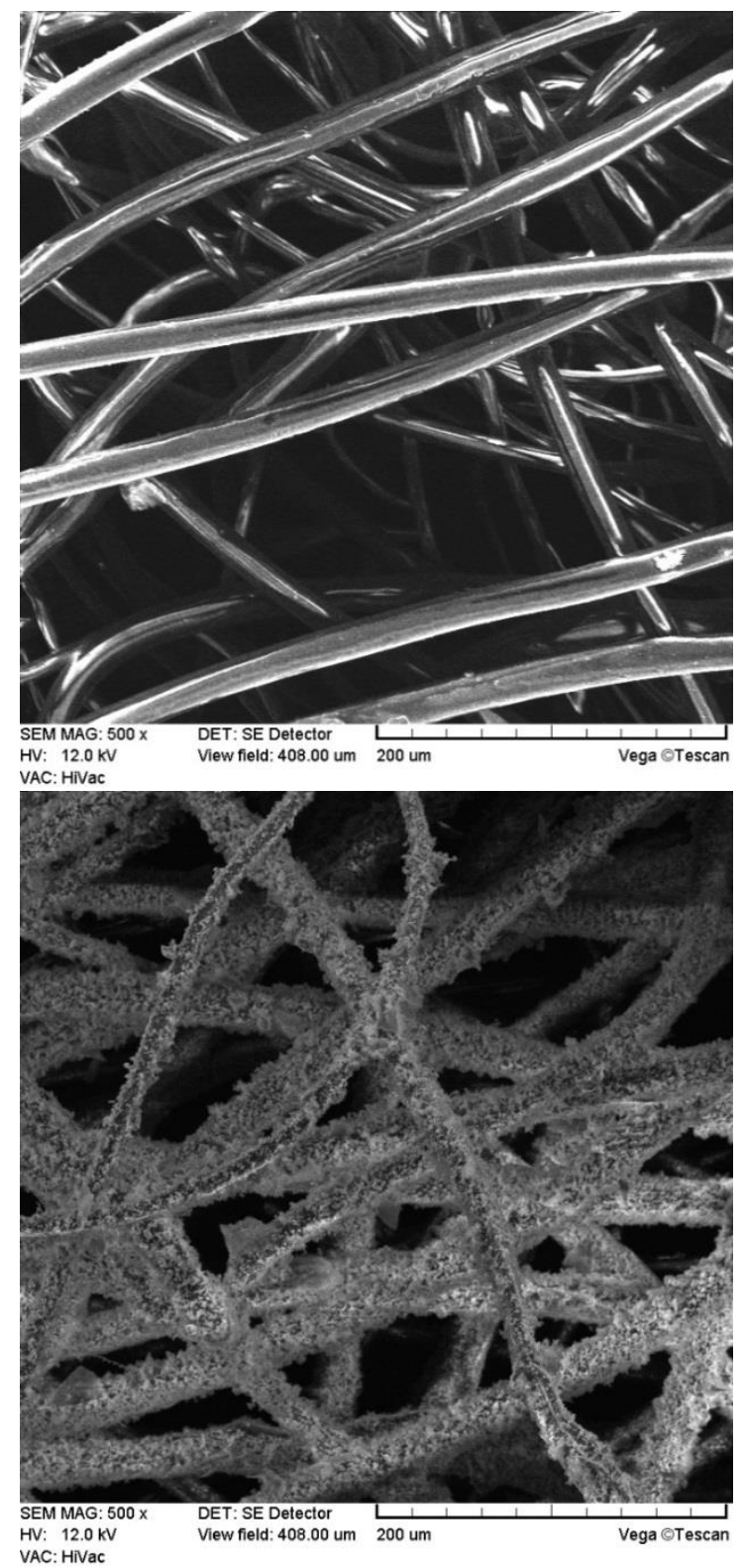

Fig. 2. SEM image of a new air purifier filter (top) and filter after a few months of operation in the winter season of 2018 (bottom) 


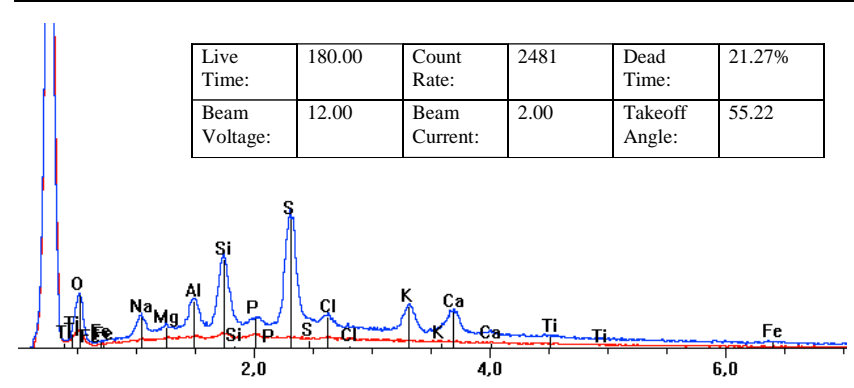

Fig. 3. Comparison of the chemical composition, determined by the EDS method, for the substances on a new filter (red line) and used filter (blue line); filter samples from figure 2

composition of the material collected on the filter allows to determine its origin. In the used filter, apart from the carbon footprint, the peak coming from sulphur has the dominant value. Sulphur has been practically absent in motor fuels for many years, which is why it can be assumed that the accumulated pollution does not come from automotive sources but from the combustion of sulphated fuels in domestic heating furnaces.

\section{Carbon nanotubes impact on plants}

\subsection{Methods and materials}

For the experiments, the seedling of cress (Lepidium sativum) has been chosen, characterized by low requirements, which allowed to eliminate the influence of other factors on the growth of the tested plants. For the tests, the seeds were selectively checked for any damage or faults. Samples were planted on Petri dishes with a diameter of $10 \mathrm{~cm}$. Two types of substrates were used. The first substrate consisted of a layer of cotton wool and sterile gauze. The second substrate was a layer of cotton wool and non-woven fabric with carbon fibres as shown in Figure 4.

300 seeds were placed on each substrate. The experiment was carried out for a week. Plants were kept at a temperature of about $23^{\circ} \mathrm{C}$. Samples were watered daily with $10 \mathrm{ml}$ of distilled water per day for 5 days. The last 2 days of the experiment the plants did not receive any water. After the experiment lasted a week, samples were taken.

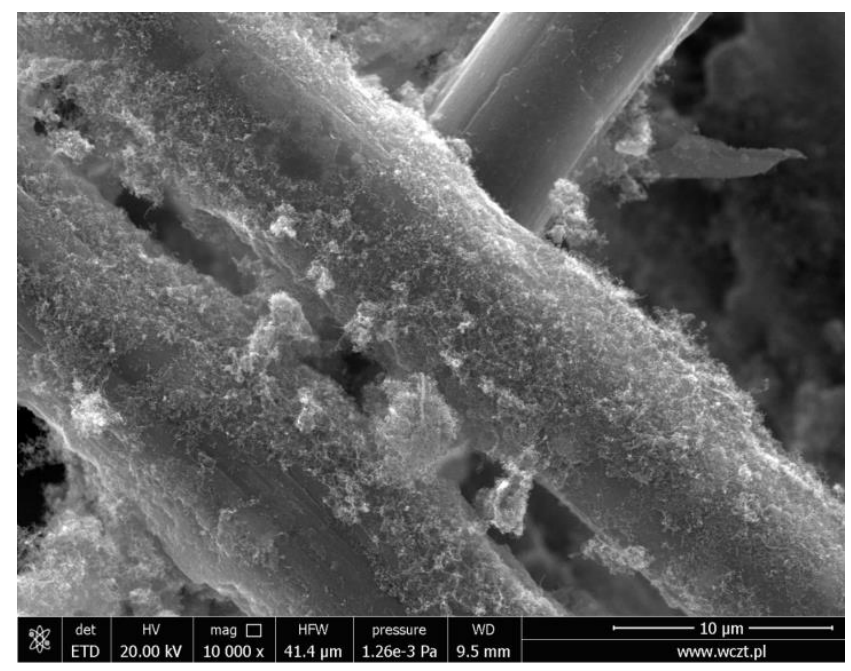

Fig. 4. Hierarchical structure of Nanoveil, a non-woven fabric made of carbon fibers with a layer of carbon nanotubes on the surface

\subsection{Results}

Figure 5 presents a comparison between the cress seeds samples cultivated on a medium without the addition of CNT and on a medium with the addition of CNT. The visual results indicate a positive effect of the presence of CNT on the intensity of germination and growth of the plant. It seems that the amount of seeds that are germinated is greater in the case of a sample grown on a substrate with CNT. Also, despite the lack of water supply in the last days of the experiment, plants grown on a substrate with the addition of CNT kept the freshness and green colour of the leaves longer. The length of the stalk and cotyledon is much larger
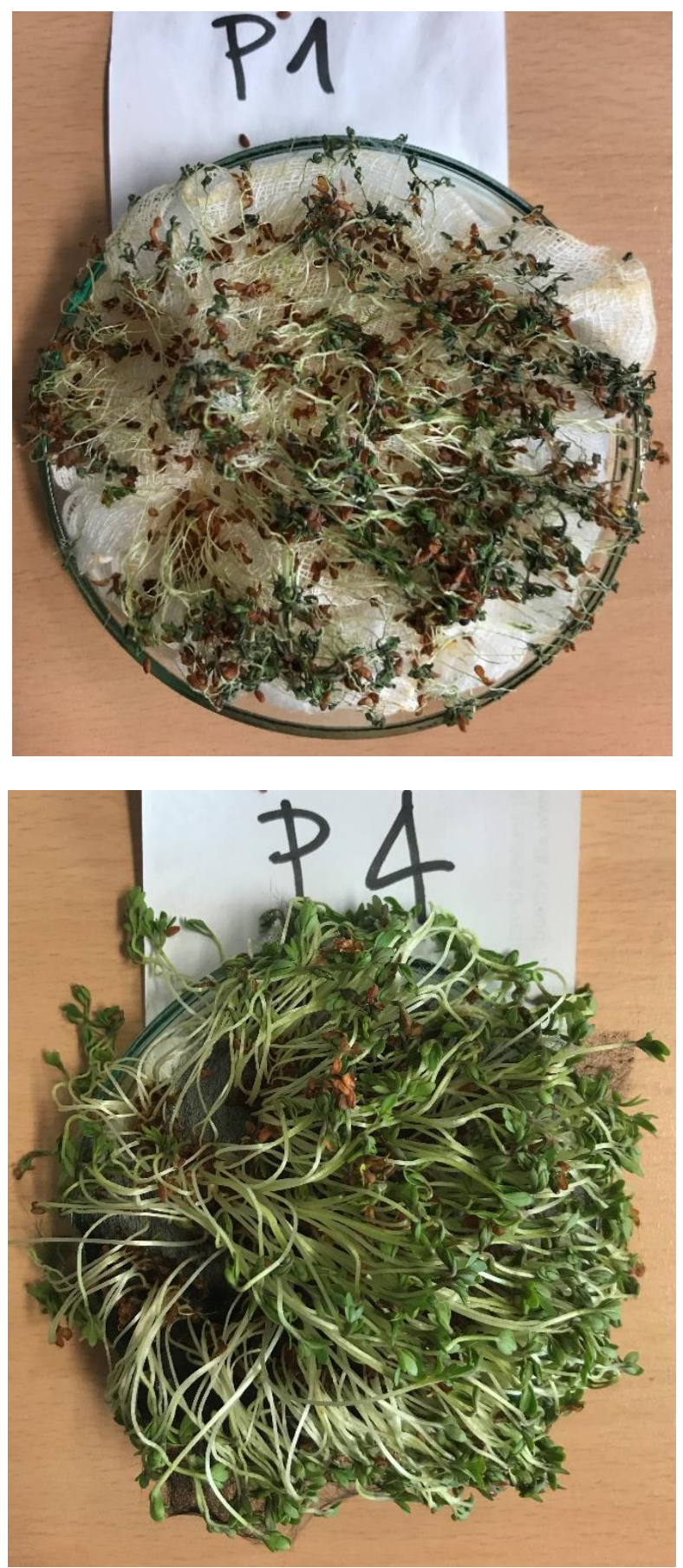

Fig. 5. Cress growth results on an ordinary substrate without CNT (on the top) and on a substrate made of carbon fiber - CNT composite (Nanoveil; on the bottom) 
in the case of plants grown on CNT substrate. However, the mechanism of action of CNT on the plant is unknown. Because of the stiffness of CNT-enriched fiber compared to the gauze on which plants were grown without the addition of CNT, it is possible that the water did not penetrate so quickly into the layer of cotton underneath the nonwoven fabric, which resulted in longer moisture retaining the substrate and thus contributed to faster increase and longer freshness of the plant grown on the substrate with the addition of CNT. However, assuming that in the early days when the plants were watered, the humidity of both substrates was similar, it seems that the CNT supplement improved the germination mechanism of plants. Thus, the positive effect of the addition of CNT in the culture medium may be stated by the improved germination of the plant, better water absorption or maintaining a certain stiffness of the stem structure for a long time despite the lack of water supply.

Figure 6 shows the Raman spectra of the cress recorded for three different parts: root, stem and leaf using a wavelength of $514.5 \mathrm{~nm}$. The band's spectrum can be attributed to the following functional groups: bands in the range of $1000-1150 \mathrm{~cm}^{-1}$ are related to polysaccharide vibrations (polysaccharides), $1150-1300 \mathrm{~cm}^{-1}$ are responsible for vibrations occurring in carotenoids, while $1450-1650 \mathrm{~cm}^{-1}$ are associated with carotenoid and chlorophyll vibration. A strong increase of these bands was observed, going from the root part through the stem to the leaf. The CNTs in the Raman spectrum show specific peaks at about $1580 \mathrm{~cm}^{-1}$. Strong Raman signals derived from unsaturated carbon bonds present in chlorophyll and carotenoids do not allow reliable confirmation of the CNT presence in the tissue of the studied plants.

\section{Bibliography}

[1] MURR, L.E., BANG, J.J., ESQUIVEL, E.V. et al. Carbon nanotubes, nanocrystal forms, and complex nanoparticle aggregates in common fuel-gas combustion sources and the ambient air. Journal of Nanoparticle Research. 2004, 6, 241-251.

[2] MURR, L.E., GUERRERO, P.A. Carbon nanotubes in wood soot. Atmospheric Science Letters. 2006, 7, 93-95.

[3] DIKIO, E.D. Morphological characterization of soot from the atmospheric combustion of diesel fuel. International Journal of Electrochemical Science. 2011, 6, 2214-2222.

[4] De VOLDER, M.F.L., TAWFICK, S.H., BAUGHMAN, R.H., HART, A.J. Carbon nanotubes: present and future commercial applications. Science. 2013, 339, 535-539.

[5] BAUGHMAN, R.H., ZAKHIDOV, A.A., DE HEER, W.A. Carbon nanotubes - the route toward applications. Science. 2002, 297, 787-792.

[6] KAŁUŻNY, J. et al. Lubricating performance of carbon nanotubes in internal combustion engines - engine tests results for CNT enriched oil. IJAT. 2017, 18(6).

[7] KAŁUŻNY, J., MERKISZ, J., KEMPA, K. et al. Friction reducing performance of carbon nanotubes covered pistons in internal combustion engines - engine test results. Combustion Engines. 2018, 172, 14-24.

[8] KOLOSNAJAJ-TABI, J. et al. Anthropogenic carbon nanotunes found in the airways of Parisian children. EBioMedicine. 2015, 2, 1697-1704.

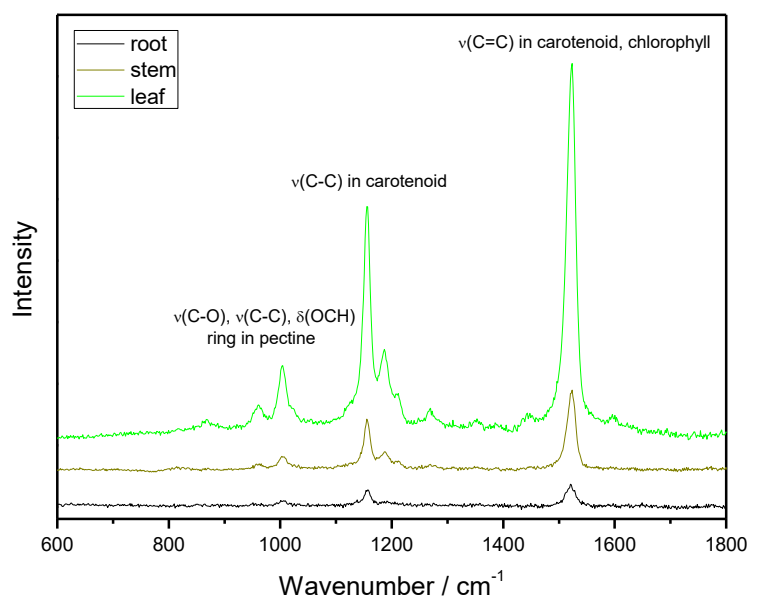

Fig. 6. The Raman spectroscopy results for the plant parts visible in Fig. 5, for the ones growing on a substrate containing CNT

\section{Conclusion}

The variety of biological interactions of carbon nanomaterials such as TNC and graphene undoubtedly requires additional knowledge and systematization. In this article we presented the results of experiments that show that when implanted into the soil, CNTs stimulate the growth of plants, which at first glance would seem to be a purely desirable effect. It is probable, however, that the presence of CNTs can stimulate the growth of selected organisms, while negatively or neutrally affecting others, which after a certain time could lead to a reduction in biodiversity, with obvious damage to the ecosystem. Our research suggests that CNTs are incorporated into plant tissue, so they can become a component of animal feed resulting in predictable secondary consequences for the environment.
[9] LAGALLY, C.D., REYNOLDS, C.C.O., GRIESHOP, A.P. et al. Carbon nanotube and fullerene emissions from sparkignited engines. Aerosol Science and Technology. 2012, 46, 156-164.

[10] MANOJ, B., SREELAKSMI, S., MOHAN, A.N., KUNJOMANA, A.G. Characterization of diesel soot from the combustion in engine by x-ray and spectroscopic techniques. International Journal of Electrochemical Science. 2012, 7, 3215-3221.

[11] SWANSON, J., FEBO, R., BOIES, A., KITTELSON, D. Fuel sulfur and iron additives contribute to the formation of carbon nanotube-like structures in an internal combustion engine. Environmental Science \& Technology Letters. 2016, 10, 364-368. DOI: 10.1021/acs.estlett.6b00313

[12] ALDAJAH, S., HAIK, Y., ELNAJJAR, E. A novel dual effect soot filtering system. Jordan Journal of Mechanical and Industrial Engineering. 2010, 4, 75-78

[13] HAIK, Y. et al. US Patent 8,480,992 B2.

[14] CINKE, M., LI, J., CHEN, B. et al. Development of metalimpregnated single walled carbon nanotubes for toxic gas contaminant control in advanced life support systems. $S A E$ Technical Paper 2003-01-2368. 2003. DOI: 10.4271/200301-2368.

[15] ZANELLO, L.P. et al. Bone cell proliferation on carbon nanotubes. Nano Letters. 2006, 6(3).

[16] LEPORE, E. et al. Spider silk reinforced by graphene or carbon nanotubes. 2D Mater. 2017, 4. 
[17] KHODAKOVSKAYA, M. et al. Carbon nanotubes are able to penetrate plant seed coat and dramatically affect seed germination and plant growth. ACS nano. 2009, 3(10), 3221 3227.

[18] KHODAKOVSKAYA M.V., KIM, B.S., KIM, J.A. et al. Carbon nanotubes as plant growth regulators: effects on tomato growth, reproductive system, and soil microbial community. Small. 2013, 9(1), 115-123. DOI: 10.1002/smll. 201201225.

[19] ZAYTSEVA, O. Analysis of phytotoxicity and plant growth stimulation by multi-walled carbon nanotubes. 2017.

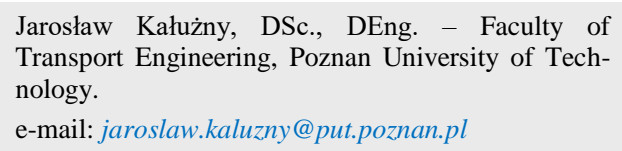

Tomasz Runka, DSc. - Faculty of Technical Physics at Poznan University of Technology.

e-mail: tomasz.runka@put.poznan.pl
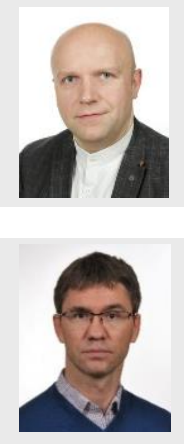

Marek Nowicki. DEng. - Faculty of Technical Physics, Poznan University of Technology.

e-mail: marek.nowicki@put.poznan.pl
[https://www.researchgate.net/publication/321265236_Anal ysis_of_phytotoxicity_and_plant_growth_stimulation_by_m ulti-walled_carbon_nanotubes]

[20] FALANA, H., NOFAL, W., NAKHLEH, H. A review article lepidium sativum (Garden cress). 2014

[21] ANDERS, A., KALINIEWICZ, Z., MARKOWSKI, P. Porównanie cech geometrycznych nasion pieprzycy siewnej (lepidium sativum 1.) z okrywą oraz poddanych obłuskiwaniu. Acta Agrophysica. 2013, 20(1), 17-28.

Natalia Idaszewska. DEng. - Faculty of Transport Engineering, Poznan University of Technology.

e-mail: natalia idaszewska@put.poznan.pl

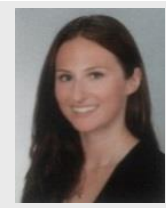

Adam Piasecki, DEng. - Faculty of Mechanical Engineering and Management at Poznan University of Technology.

e-mail: adam.piasecki@put.poznan.pl

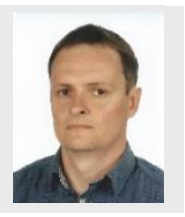

Prof. Jerzy Merkisz, DSc., DEng. - Faculty of Transport Engineering, Poznan University of Technology.

e-mail:jerzy.merkisz@put.poznan.pl 